\section{Prospects of Storage and Pumped- Storage Hydropower for Enhancing Integrated Nepal Power Systems}

\author{
Neeraj Kumar Sah, Madhab Uprety, \\ Sangharsha Bhandari, Jeevika Khadka, \\ Prativa Kharel, Saurav Suman and \\ Ramesh Kumar Maskey
}
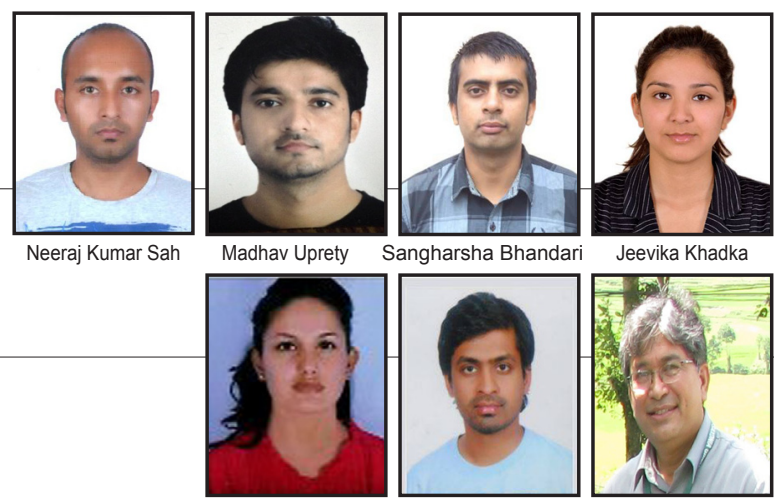

Prativa kharel

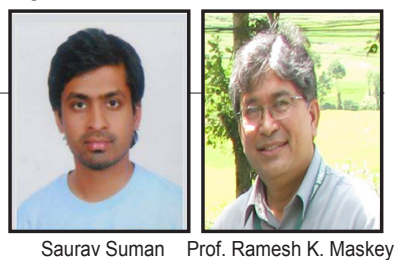

Abstract: An Integrated Power System (IPS) should have electrical energy generating plants for base load (e.g., nuclear and thermal plants) and peak load (e.g., hydropower plants) so that they can work in coordination in such a way that the demand is met in time. In Nepal, the Integrated Nepal Power System (INPS) is a hydro-dominated system where the base and intermediate power demands are covered primarily by run-of-river hydropower plants and the peak demand by seasonal storage and several diesel power plants of lower capacity. The INPS should have sufficient natural storage and forced storage power plants to improve the system's reliability. On top of that, daily peak electrical demand could also be adequately covered by demand-side management, using a pumped-storage hydropower plant that can employ a system's surplus energy during low demand period for pumping. To rectify this extreme imbalance of installed capacity in Nepal, this paper explores the prospect of storage and pumped-storage power plants for enhancing INPS. A case study of Rupa-Begnas pumped-storage hydropower is highlighted for these purposes.

Key words: Integrated power system, grid regulation, storage hydropower, pumped-storage hydropower, Nepal

\section{Introduction}

There are a variety of power plants like nuclear, fossil fuel (coal, gas, oil), and run-of-river hydropower to fulfill daily electrical energy demand. But when it comes to adjusting the output of these plants with the rapidly changing demand on electricity, they seem unsuitable (Ilyinykh nd). The power plants listed above are generally used to fulfill the base-load and do not always fulfill the demand at peak periods. Or, in other cases, these plants collective produce surplus electricity which can result in plant shutdowns, environmental pollution, spillage of energy, and deterioration of plant economy.

The Integrated Nepal Power System (INPS) is dominated by run-of- river hydropower plants (NEA 2012). Electricity from such conventional power plants has to be used as soon as it is generated; this power cannot be stored. This is why grid control and electricity dispatching systems are important; they have to balance the demand for electricity with supply. When electricity supply and demand fall out of balance, problems occur. Therefore, it is important to store electrical energy or supply electricity through reserves to maintain a balance between system demand and supply.

Furthermore, Nepal is marching towards production of more green energy like solar and wind. However, the green energy potential is dependent on environmental variables and has not yet demonstrated much promise in making up the power balance (Boyson 2010). But, green energy should continue to be developed as a means to diversify Nepal's electricity generation portfolio. In the meantime, this scenario of electricity generation in Nepal the optimization of the use of transmission line infrastructure, and capturing surplus energy by incorporating pumped-storage power plants into INPS

\begin{tabular}{|c|l|c|}
\hline S. No. & \multicolumn{1}{|c|}{ Project } & Capacity (MW) \\
\hline 1 & West Seti & 750 \\
\hline 2 & BudhiGandaki & 600 \\
\hline 3 & Kali Gandaki II & 660 \\
\hline 4 & KarnaliChisapani & 10,800 \\
\hline 5 & Pancheswor & 6,480 \\
\hline 6 & DudhKoshi & 510 \\
\hline 7 & Kulekhani III & 14 \\
\hline 8 & AndhiKhola & 180 \\
\hline 9 & LangtangKhola & 218 \\
\hline 10 & MadiIshaneswor & 86 \\
\hline 11 & Kankai & 60 \\
\hline 12 & Upper Seti & 140 \\
\hline & Total & 20,498 \\
\hline & \multicolumn{2}{|c|}{ (Source: NEA Annual Report, 2013; Hydropower in } \\
Table 1: Storage Projects of Nepal & \\
\hline
\end{tabular}

Critical Need and Prospects of Storage Type Hydropower Projects

Load shedding in Nepal is occurring mostly at evening and morning times and resulting from Nepal's lack of ample storage-type projects to operate when power demands are highest. The IPS of other countries like Norway, Sweden, United States, and China all rely on storage projects to manage peak demand. Among all 
the storage plants possible, hydro storage is the most suitable because it is flexible and more efficient; as well, it is less costly and starts up quickly when power is needed (National Hydropower Association). The annual peak power demand in Nepal is steadily increasing. In 201112, power demand in Nepal grew $8.5 \%$ in 2011-2012, and there is no reason to feel this figure willnot continue to rise (NEA 2012).

Hence, it is imperative to develop storage power projects to fulfill the country's need for peak load demand and to balance its system of electricity generation. There is great potential for storage in Nepal: almost half of Nepal's technical capacity of hydropower (20,498 MW) falls under storage type projects.

\section{Pumped-Storage Hydropower (PSH) and its Benefits}

Pumped Storage Hydropower (PSH) is a type of hydropower used generally for load balancing, but it does not add to installed capacity. The basic idea of PSH is simple. It stores energy in the form of hydraulic potential energy of water, pumping water from a lower elevation reservoir to a higher elevation reservoir using low cost off-peak energy. When recovery of energy is required at a peak period, the water is released from the upper reservoir to the lower reservoir through turbines which drive electrical generators to produce electricity (Pumped-Storage Projects 2014). Although the losses of pumping make the plant a net consumer of energy, overall the system increases revenue by selling more electricity during periods of peak demand when electricity prices are highest. The system is economical also because it diminishes load variations on the power grid by helping base-load power plants operate more efficiently at peak demand (Ilyinykh).

A PSH contributes to the total peaking capacity of the system. PSHs help in load and frequency regulation by continuously matching system generation with the system load. These plants also acts as standby and spinning reserves, as the operating can be synchronized and brought to full load in a short time. PSHs in spinning and standby reserve modes are available to provide system frequency control, and to respond to and correct low frequency occurrences. A PSH can also operate in condenser mode to generate or to absorb reactive power (phase compensator mode) as may be required for system voltage regulation. Furthermore, a PSH contributes to system reliability and restart in case of a system-wide failure of transmission or generation (Lohiya 2009).

\section{Vital need of PSH in Nepal}

In Nepal, there is a considerable gap between demand and supply of electricity. But even during this time of energy crisis, the INPS spills energy during off-peak hours. Therefore, it would seem obvious, given this situation, that one or two pumped-storage plant would be a major boon to grid operation in terms of efficient and optimal use of available electricity.

The analysis of daily load curve (figure 1) of INPS shows that it has surplus energy during the night time and this surplus energy is superfluous because there is no demand at that time. Countries around the world face this same challenge, but they use different types of electrical energy storage to store the off-peak surplus energy so that it is available during peak demand. Among all the storage techniques available, pumped-

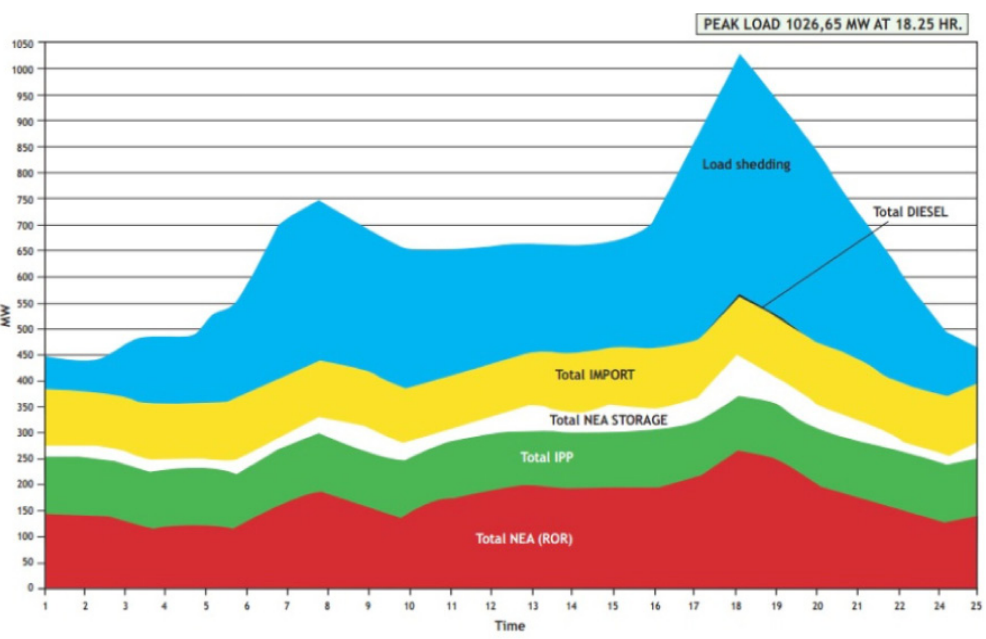

Figure 1: Load Curve of Peak Load Day (Jan 13,2012) storage is the largest-capacity form of grid energy storage available. As of March 2012, the Electric Power Research Institute (EPRI) reports that PSH accounts for more than $99 \%$ of bulk storage capacity worldwide,

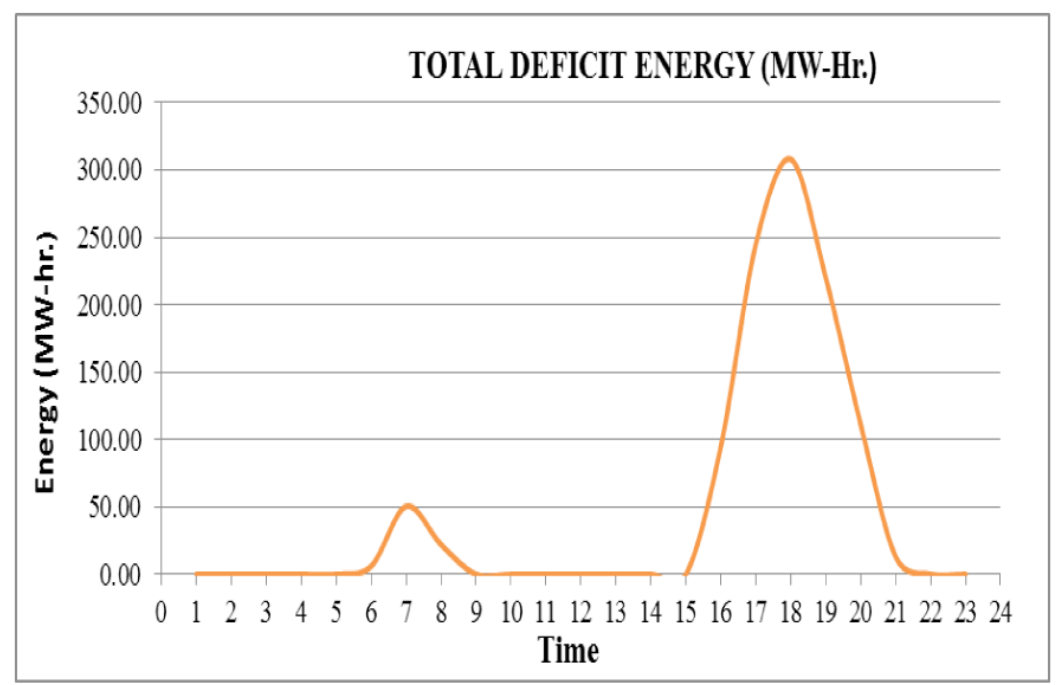

Figure 2: Total Deficit Energy (1070.61 MWh) 
representing around 127,000 MW (PumpedStorage Hydroelectricity 2012). So, even with an increase in generation from other types of plants, pumped-storage plants will still see increased usage and importance in the coming years.

\section{Prospects of PSH}

The prospect of a pumped-storage plant in Nepal is greatly dependent on the present and future energy status of Nepal. The daily load curve of INPS in 2012 (figure 1) assumes constant power production of 400 MW (dry period) and 680 MW (wet period) is shown below (figures 2 and 3):

The result shows, there is enough excess energy to overcome the energy deficits during the wet season. However, this situation doesn't hold true during dry periods-for now. During dry periods, much less excess energy is available. Thus the pumped-storage scheme at present can only be envisioned for seasonal peaking times (wet season).

But, at present there are number of projects in the pipeline and some with a large capacity. Thus a pumped-storage plant can operate for daily peaking after implementation of those projects. However, in Nepal, the capacity of a pumped storage will vastly depend on the amount of excess energy available from run-ofriver projects or green energy sources to pump back the water.

\section{A Case Study of Begnas-Rupa Pumped- Storage Hydropower}

Rupa Lake and Begnas Lake are located in Sundaridanda of Kaski district, Nepal (figure 4). A topographical survey at the site showed that the gross head between two reservoirs (Begnas-upper; Rupalower) is 60 meters.

A storage volume-elevation curve and area-elevation curve were obtained using survey data. Both the curves shown in the figures below ( 6 and 7 ) are drawn as a function of the lower reservoir (Sah et al. 2013).

A bathymetric survey of Begnas Lake and Rupa Lake as shown in the figures below ( 8 and 9) was used to determine the reservoir capacity (Thapa, Banjara, \& Shrestha 2011). The reservoir and plant capacity were determined using a multi-disciplinary approach which encompassed reservoir capacity (Rupa Lake), excess energy available to pump water into Begnas Lake, and operation hours of the plant. The graph of elevation versus inundation area and that of storage volume versus elevation are shown in figures 6

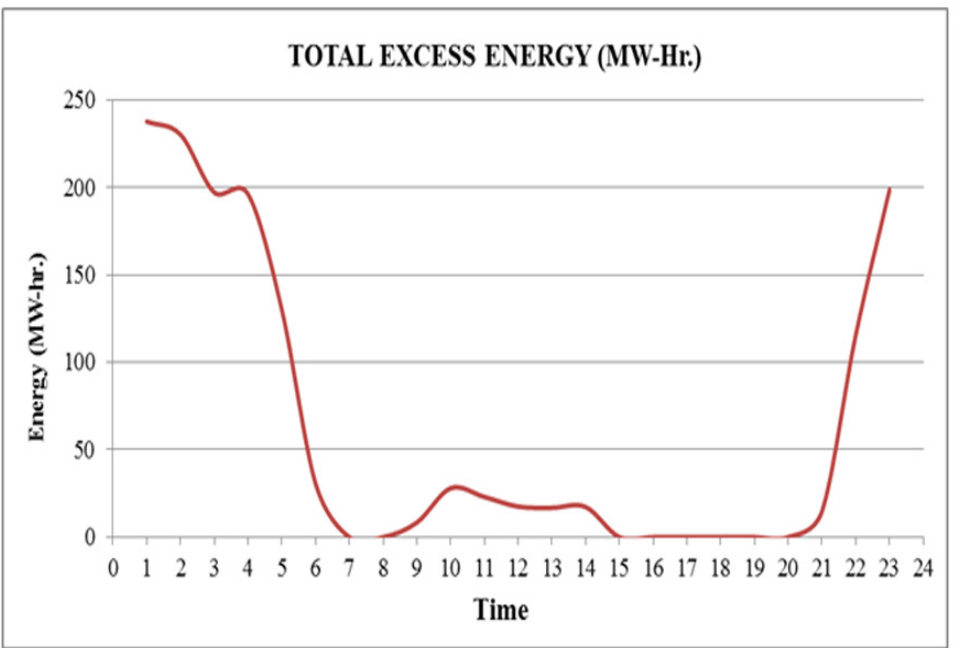

Figure 3: Total Excess Energy (1460.76 MWh.)

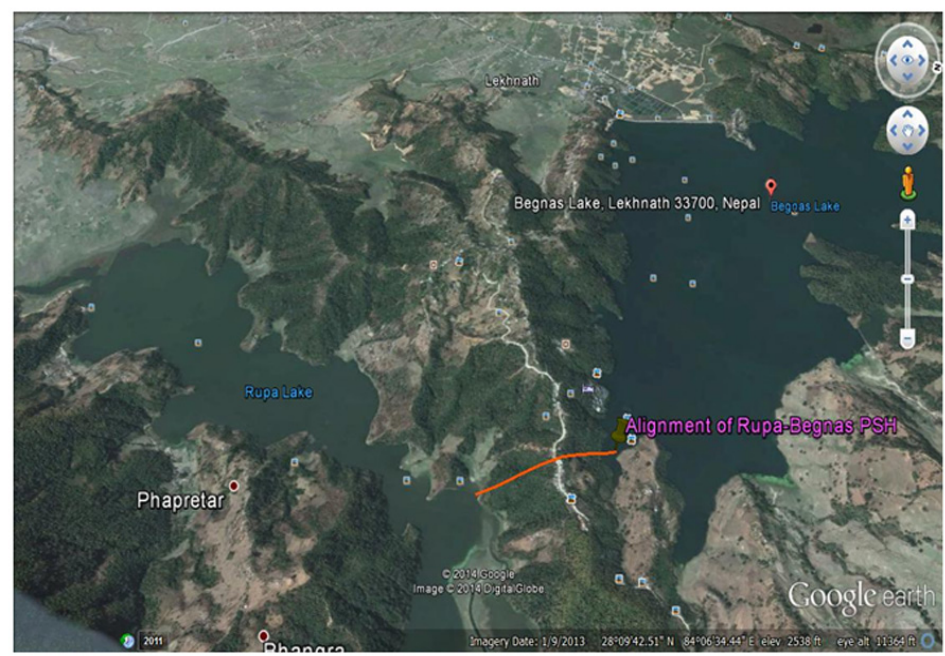

Figure 4: Google Map of Project Area

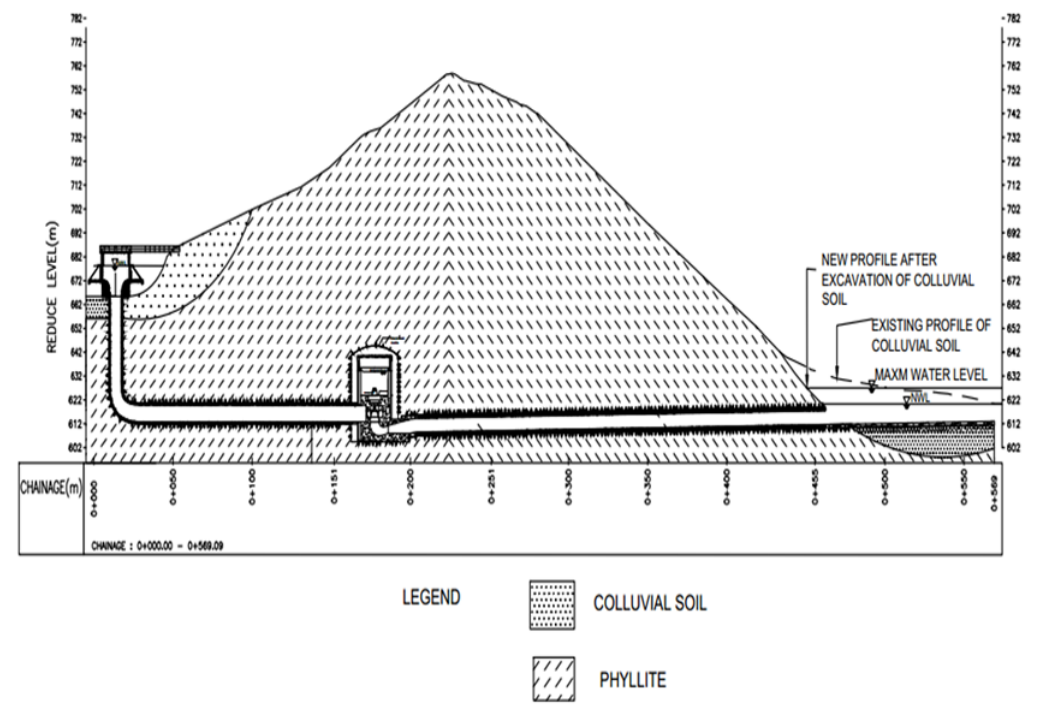

Figure 5: Cross-section of PSH showing geology and Tunnel Alignment and 7 , respectively.

After performing several trials, the plant capacity was fixed at $100 \mathrm{MW}$ which can operate forfive hours. A five hour operation of the plant will utilize 4.1 million cubic 
meters (MCM) of water, resulting in a 1.5 meter drawdown of Begnas Lake (figure 8) at a design discharge of $227 \mathrm{~m} 3 / \mathrm{s}$. This drawdown will inundate approximately 60 hectares of farmland upstream of Rupa Lake (figure 6). Downstream of Rupa Lake, an $8.0 \mathrm{~m}$ high earthen dam is required to accumulate 7.0 MCM of water which is kept to preserve pisci-culture and irrigation. A reversible pump-turbine returns $4.1 \mathrm{MCM}$ of water in 5.5 hours. Other combinations of smaller capacities of pump can be used to pump back the water using excess energy available from INPS at different times of the day.

The capacity of plant can be increased by two fold by decreasing the operating hours to three. The current electricity tariff is not encouraging for this type of hydropower scheme because energy tariffs at peak demand are not high enough to make this type of project profitable.

\section{Conclusion}

It is encouraging that Nepal is focusing more on hydropower development; there are number of projects to be commissioned within the next couple of years. However, it would be naïve to think that these pipeline projects will eliminate load shedding. Nepal's load shedding problem cannot be sorted out until there are storage and pumped-storage power plant in IPS to cope with peak demand. Storage projects will be used primarily to fulfill peak demand and while pumped-storage will save excess energy and help in load balancing at emergency times. At least one or two such pumped projects are vital for the effective grid operation in Nepal. Pumped-storage is itself a new concept for Nepal's energy system and its adoption is crucial to help us deal with peak demand that continues to grow. Without this type of scheme, Nepal's energy loads cannot be balanced and the country will continue to suffer power cuts while wasting excess energy that might be used other times of day. Furthermore, solar and wind power plants can also be connected to the grid and developed in tandem with pumped-storage plants. PSH can be a suitable tool to mitigate the importance of other types of power plants. Yes, there are many associated problems with storage projects (e.g., inundation of land, environmental impacts, etc.), but with technological advancements, sound policies, and trans-boundary cooperation, it may be possible to minimize and mitigate those challenges and bring a more efficient and diverse electricity portfolio to Nepal.

\section{Acknowledgments}

We express our gratitude to Er. Mahesh Thapa, Er. Bigyan Banjara, Er. Sanjeevan Shrestha, people of

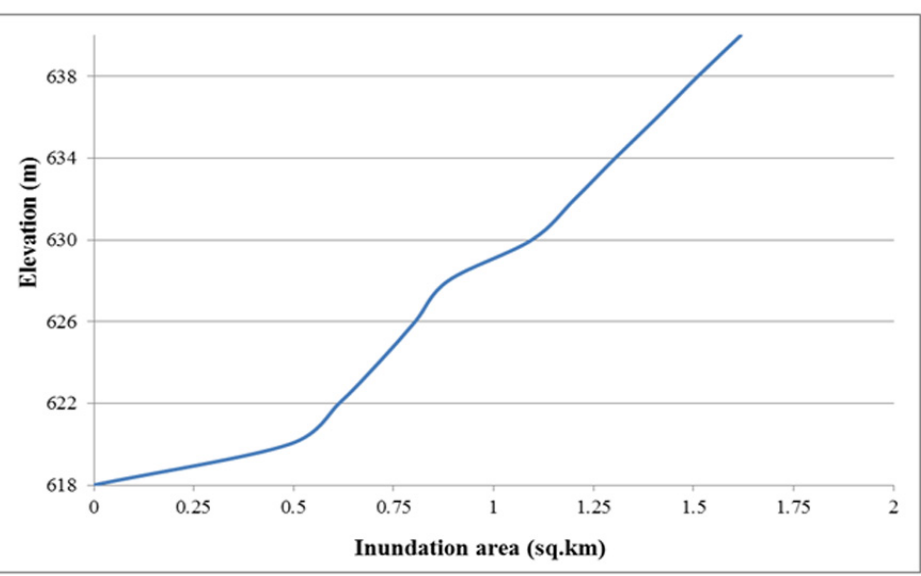

Figure 6: Graph of elevation vs inundation area

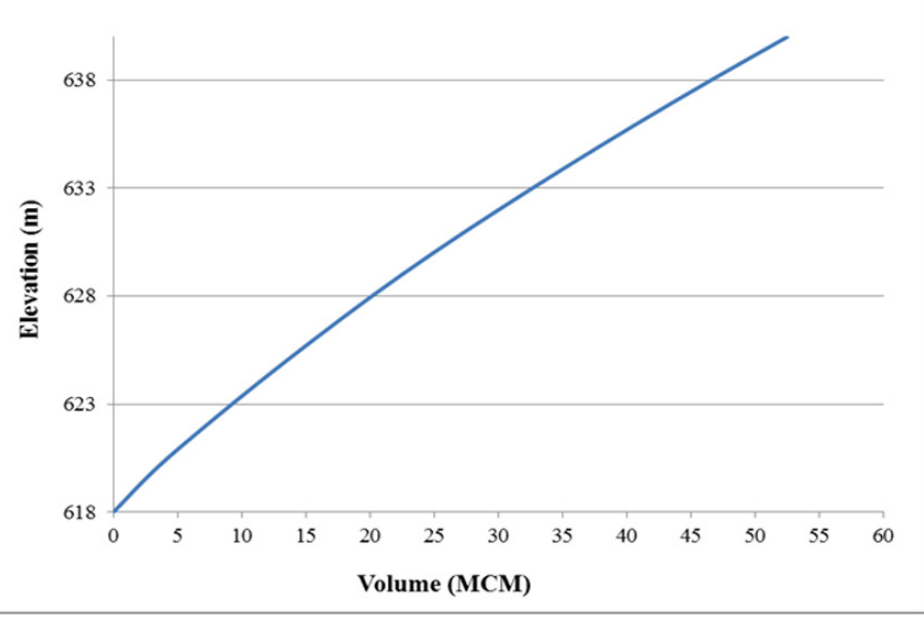

Figure 7: Storage volume vs elevation curve

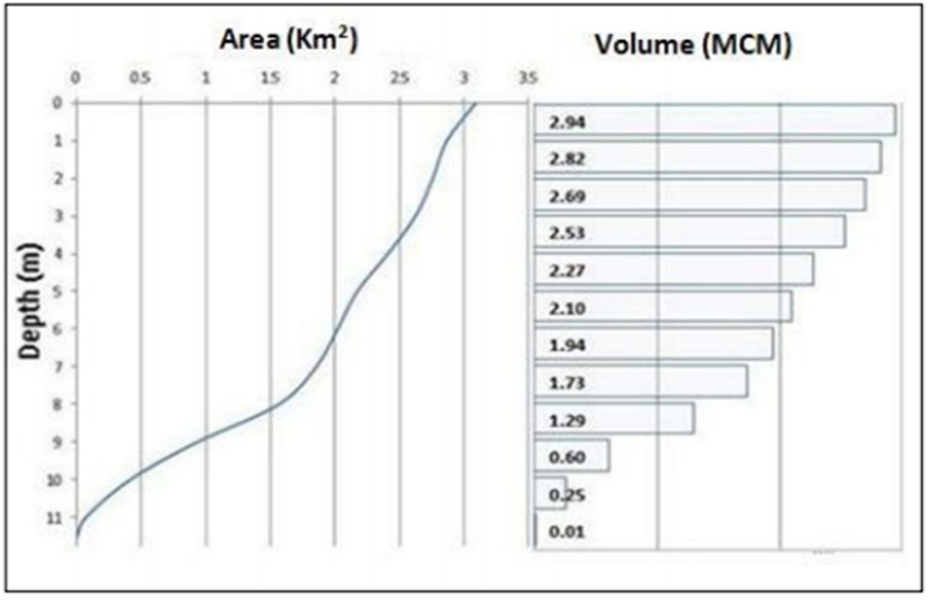

Figure 8: Hypsographic Curve of Begnas Lake
Sundaridanda, Kaski district and Department of Civil and Geomatics Engineering, Kathmandu University for their support.

The study was undertaken in partial fulfillment of a Bachelor's of Engineering in Civil Engineering at Kathmandu University, Nepal.

Neeraj Kumar Sah completed his BE in Civil Engineering (with specialization in hydropower) from Kath- 


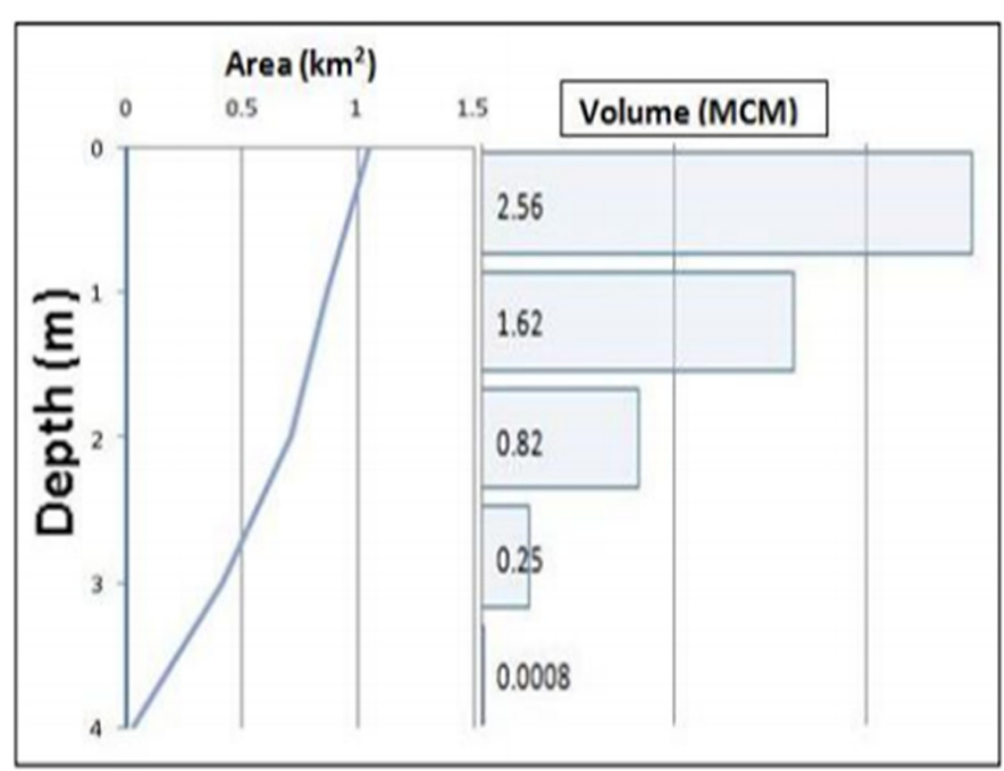

Figure 9: Hypsographic Curve of Rupa Lake

mandu University in 2013. He is working as a research assistant at the Centre for Excellence in Production and Transportation of Electrical Energy (CEPTE/KU), an Energy R\&D unit within the School of Engineering at Kathmandu University, Nepal.

Corresponding address:neeraj_sah22@outlook.com

Madhab Uprety completed his BE in Civil Engineering (with specialization in hydropower) from Kathmandu University, Nepal in 2013. He is working for theBuilding Design Authority (BDA), Kathmandu, Nepal.

Sangharsha Bhandari completed his BE in civil Engineering (with specialization in hydropower) from Kathmandu University, Nepal in 2013. He is working at the Hewa Khola Hydropower Project in Ilam, Nepal.

Jeevika Khadka completed her BE in Civil Engineering (with specialization in hydropower) from Kathmandu University, Nepal in 2013. She works for Hydro Consult, Kathmandu, Nepal.

Prativa Kharel completed her BE in Civil Engineering (with specialization in hydropower) from Kathmandu University, Nepal in 2013. She is working at Sanvi Energy Pvt. Ltd., Kathmandu, Nepal.

Saurav Suman completed his BE in Civil Engineering (with specialization in hydropower) from Kathmandu University, Nepal in 2013. He works for ERMC-NESS $J V$, a project management consultant of high powered committee for Integrated Development of Bagmati Civilization in Nepal.

Prof. Dr. Ing. Ramesh Kumar Maskey completed intermediate in Electrical Engineering from the Institute of Engineering, Tribhuvan University, Nepal in 1979. He has a MSc. in Civil Hydropower Engineering from Beylorussian Polytechnic Institute, Beylorussia (1987) and MSc. in Resources Engineering from Uni- versity of Karlsruhe, Germany (1996). Since March 2006, Dr. Maskey has worked as a professor of civil engineering at Kathmandu University (KU), Nepal, where he also serves as the founder Head of Department of Civil and Geomatics Engineering. He is the coordinator of Centre for Excellence in Production and Transportation of Electrical Energy (CEPTE/KU), an Energy $R \& D$ unit, within the School of Engineering, Kathmandu University and is an activity leader of the project Design and Development of a minigrid for efficient use of distributed hydropower systems from CEPTE/KU. Currently, he has been appointed as Associate Dean for the School of Engineering for academic and administrative responsibility of the school.

\section{References}

Baral, S. (2012). Fundamentals of Hydropower Engineering. Kathmandu : Engineering and Educational Services Pvt. Ltd. .

Boyson, A. (2010). Pumped-Storage Hydroelectricity. California: Standford University.

Ilyinykh, I. (n.d.). Hydroelectric Stations. Moscow: MIR. Lohiya, A. K. (2009). Electrical Energy Storage-Large Scale. Manipal: MIT.

Mosony, E. (n.d.). Water Power Development.

National Hydropower Association. (n.d.). Retrieved February 2014, from Hydro Technology: http://www. hydro.org/tech-and-policy/technology/PumpedStorage/

NEA. (2012). Annual Report. Kathmandu: NEA.

Sah, N. K., Uprety, M., Bhandari, S., Khadka, J., \& Kharel, P. (2013). Potentiality of Pumped-Storage Hydropower Scheme in Nepal: A case study of Begnas and Rupa Lake. Kathmandu.

Thapa, M., Banjara, B., \& Shrestha, S. (2011). Lake Morphometry and Hydrologic Modeling of Begnas and Rupa Lakes' Watershed. Kathmandu University, DCGE. Kathmandu: KU.

Pumped-Storage Hydroelectricity. (2012, July). Retrieved February 2014, from Wikipedia: file://D:/ Research\%20article/research\%2oarticle_neeraj/ Pumped-Storage\%2ohydroelectricity\%20-\%20 Wikipedia,\%20the\%2ofree\%2oencyclopedia.htm

Pumped-Storage Projects. (2014, February 03). Retrieved February 2014, from FERC: http://www. ferc.gov/industries/hydropower/gen-info/licensing/ pump-storage.asp

Hydropower in Nepal. (n.d.). Retrieved February 12, 2014, from www.ippan.org.np: http://www.ippan. org.np/HPinNepal.html 